\title{
Ngabandungan Banda Indung Interpretasi Kepercayaan Masyarakat Sunda Rancakalong melalui Seni Visual
}

\author{
Rini Maulina, Setiawan Sabana, Nuning Yanti Damayanti, Teddi Muhtadin \\ Program Studi Doktor Ilmu Seni Rupa dan Desain, \\ Fakultas Seni Rupa dan Desain \\ Institut Teknologi Bandung \\ Gedung Seni Rupa, Jl. Ganesha 10 Bandung \\ Tlp. 0222534104 \\ Program Studi Fakultas Ilmu Budaya \\ Universitas Padjadjaran \\ Jl. Raya Bandung Sumedang KM 21, Jatinangor 45363 \\ Tlp. (022) 7796482 E-mail: rini.maulina@email.unikom.ac.id
}

\begin{abstract}
Indung (mother) in Sundanese culture is not only meaningful as a mother who gives birth, but has a broad meaning and contains motherhood. Sundanese people have a tradition of appreciating the indung, seen from the mention of the indung in Paribasa, Babasan, Carita Pantun, and mythology. The maternal nature of Sunan Ambu, Dayang Sumbi and Nyi Sri Pohaci, was placed in the highest position as a glorification of the indung. The results of the study showed that the philosophy contained in the traditional ceremony of Ngalaksa in Rancakalong, Sumedang, contains the meaning of broad indung, interpreted into the form of visual artwork "Ngabandungan Banda Indung", based on the problem of interpretation the meaning of the mother in visual artwork has been limited to mothers who give birth. Using the Art Based Research method, the creation of research-based artwork. Aimed at interpretation of the wider meaning of the land in the form of the depiction of the banda indung (mother's wealth) such as rice plants, honje, Kawung, Kalapa, jagong, with the depiction of batik, using glass painting techniques.
\end{abstract}

Keywords: Art Based Research, Banda Indung, Nyi Sri Pohaci, Rancakalong, Visual Art

\begin{abstract}
ABSTRAK
Indung (ibu) dalam budaya Sunda tidak hanya bermakna sebagai ibu yang melahirkan, tapi memiliki makna yang luas dan mengandung sifat keibuan. Masyarakat Sunda memiliki tradisi lebih menghargai indung, terlihat dari penyebutan indung pada paribasa, babasan, carita pantun, dan mitologi. Sifat keibuan terdapat pada Sunan Ambu, Dayang Sumbi, dan Nyi Sri Pohaci, ditempatkan pada posisi tertinggi sebagai pemuliaan indung. Hasil penelitian menunjukkan falsafah yang terkandung dalam upacara adat Ngalaksa di Rancakalong, Sumedang, mengandung makna indung yang luas, diinterpretasikan ke dalam bentuk karya seni visual Ngabandungan Banda Indung, berdasarkan permasalahan interpretasi terhadap makna ibu dalam karya seni visual selama ini terbatas pada ibu yang melahirkan. Menggunakan metode Art Based Research, penciptaan karya seni berbasis penelitian. Bertujuan sebagai interpretasi makna indung yang lebih luas berupa penggambaran banda indung (kekayaan Ibu) seperti tanaman padi, honje, kawung, kalapa, jagong, dengan penggambaran batik, menggunakan teknik lukis kaca.
\end{abstract}

Kata Kunci: Art Based Research, Banda Indung, Nyi Sri Pohaci, Rancakalong, Seni Visual. 


\section{PENDAHULUAN}

Semua budaya di dunia mengenal ibu dan cenderung ditafsirkan sebagai ibu biologis, perempuan yang mengandung dan melahirkan. Dalam budaya Sunda, nama panggilan untuk ibu yaitu indung, memiliki berbagai pemahaman. Secara umum indung dipahami sebagai ibu, namun berdasarkan literatur apabila ditinjau lebih dalam, indung tidak terbatas sebagai ibu, indung dapat berarti sifat, peran, simbol, falsafah dan sebagainya.

Indung terkandung dalam falsafah dan kosmologi budaya Sunda yang terdapat pada waditra alat musik tradisional Sunda, paribasa, babasan, carita pantun, dan mitologi. Indung yang terdapat pada paribasa seperti indung nu ngakandung bapa nu ngayuga, indung tungguling rahayu bapa pujaning waluya. Indung yang terdapat pada kosmologi seperti pada carita pantun Sri Sadana dan kosmologi masyarakat Kanekes Baduy Dalam, siklus penciptaan manusia, juga terdapat tokoh indung pada kisah mitologi seperti Dayang Sumbi, Sunan Ambu, dan Nyi Sri Pohaci. Spiritualitas Sunda melalui teks Sri Sadana adalah spiritualitas ibu. Spiritualitas yang menjunjung tinggi perempuan. Keberadaan perempuan dalam teks Sri Sadana menjadi bukti penting bahwasanya alam pikiran orang Sunda menempatkan perempuan pada posisi sentral (Tohari, 2013, hlm. 21).

Indung dalam persepsi tradisional masyarakat Sunda, menjadi sosok sentral spiritual urang Sunda. Indung menjadi simbol kesempurnaan bagi pencapaian spiritualitas yang dihayati dalam kehidupan sehari-hari sebagai tindakan memuliakan indung.
Memuliakan indung oleh masyarakat Sunda juga diwujudkan dalam bentuk upacara tradisi pemujaan terhadap Nyi Sri Pohaci atau Sanghyang Sri. Ritual pemujaan tersebut diantaranya yaitu upacara adat Ngalaksa yang dilakukan oleh masyarakat Sunda Desa Rancakalong, Kecamatan Rancakalong, Kabupaten Sumedang. Indung yang terkandung dalam falsafah dan kosmologi mewujud dalam bentuk simbol yang terdapat pada artefak kebudayaan Sunda, sehingga maknanya tidak terlihat, dan maknanya harus dicari. Prawira (2017, hlm. 13) menyatakan, Manusia senantiasa mencari arti pada bendabenda dan gejala-gejala yang mengelilinginya dengan tepat atau tidak tepat, benar atau tidak, manusia berusaha memberikan arti kepada benda-benda atau gejala-gejala tadi.

Mencari indung adalah upaya untuk mencari tahu makna indung yang lebih luas dalam budaya Sunda, untuk kemudian dituangkan ke dalam bentuk karya seni visual, hal tersebut berdasarkan dari permasalahan interpretasi terhadap makna ibu dalam karya seni visual yang terdapat pada karya seni lukis, patung, dan lainnya terbatas pada makna ibu biologis, mengandung dan melahirkan, sehingga karya seni yang menggambaran tokoh ibu dengan kegiatan afeksi ibu dan anak seperti kegiatan menyusui, menggendong, memeluk banyak ditemukan.

Tujuan dari penciptaan karya seni visual yaitu untuk menginterpretasikan makna indung yang terdapat pada kepercayaan masyarakat Rancakalong terhadap upacara adat Ngalaksa, yaitu pemujaan terhadap Nyi Sri Pohaci, sebagai upaya visualisasi makna 
indung yang lebih luas dan tidak terbatas dari makna indung yang mengandung dan melahirkan.

Karya seni visual yang dibuat berjudul Ngabandungan Banda Indung, merupakan hasil penelitian melalui pengumpulan data wawancara dan studi kepustakaan yang digunakan sebagai konsep karya seni visual dengan konsep visual batik parahyangan sebagai bagian dari estetika Sunda. Metode Art Based Research digunakan karena penciptaan karya seni visual yang dilakukan berdasarkan dari hasil penelitian. Interpretasi karya yang dihasilkan dari data-data penelitian berupa penggambaran falsafah banda indung (kekayaan Ibu) yang terdapat di daerah Rancakalong seperti tanaman padi, honje, kawung, kelapa, jagung dan pemandangan alam pegunungan dengan teknik gambar batik parahyangan dan teknik lukis kaca.

Karya tersebut telah dipamerkan pada pameran internasional Reinterpretation of Mooi Indie di Gallery R FSRD Universitas Trisakti, Jakarta Barat, yang diselenggarakan pada 26 April hingga 10 Mei 2019, sebagai kontribusi penelitian yang telah dilakukan.

\section{METODE}

Art Based Research (ABR) digunakan sebagai metode penciptaan karya seni visual Ngabandungan Banda Indung. ABR merupakan metode penciptaan karya seni visual yang digunakan dalam penciptaan karya seni berdasarkan kepada hasil penelitian, Leavy (2015, hal. 10) menyatakan
"ABR practices are a set of methodological tools used by qualitative researchers across the disciplines during all phases of social research, including data collection, analysis, interpretation, and representation".

Proses penelitian yang dilakukan pada metode ABR menggunakan cara penelitian kualitatif seperti pengumpulan data, analisis, interpretasi, dan representasi. Berkaitan dengan hal tersebut, Leavy (2015, hal. 10) menyatakan "These emerging tools adapt the tenets of the creative arts in order to address social research questions in holistic and engaged ways in which theory and practice are intertwined." Artinya Metode ABR merupakan metode yang dapat mengadaptasi prinsip-prinsip seni kreatif untuk menjawab pertanyaanpertanyaan penelitian sosial secara holistik dan di mana teori dan praktik saling terkait.

Pada penciptaan karya seni visual berjudul Ngabandungan Banda Indung, dilakukan penelitian terlebih dahulu sebelum melakukan proses penciptaan karya, mengumpulkan data-data dari literatur dan wawancara. Wawancara dilakukan dengan Bapak Jeje sebagai tokoh masyarakat dan pemimpin upacara Ngalaksa di Desa Rancakalong, Kec. Rancakalong, Kab. Sumedang, pada tanggal 31 Maret 2019.

Tujuan dari wawancara yaitu untuk mendapatkan informasi mengenai Indung dalam kebudayaan masyarakat Desa Rancakalong. Isi perbincangan menelaah hubungan indung sebagai falsafah hidup dengan pelaksanaan upacara adat Ngalaksa, serta untuk mendapatkan pemaknaan indung yang terkandung dalam kepercayan 
masyarakat Sunda Desa Rancakalong terhadap penghormatan pada Nyi Sri Pohaci.

Hasil wawancara kemudian dianalisis dan diinterpretasikan dalam bentuk karya seni visual.

"There are many different ways visual arts can be used during analysis and interpretation. For a final example, one may create visual field notes during data collection and/or analysis, mirroring the process of textbased memo notes in ethnography" (Leavy, 2015, hlm. 174).

Hal yang dikerjakan seniman dalam mengeksplorasi medium karya seni itu merupakan catatan penelitiannya. Pengodean indung dalam eskplorasi perupaannya dalam bentuk karya itu merupakan praktek penggunaan metode visual art.

"Visual art techniques are now being used in methodological approaches to interpretation. The process of conducting research is always a meaningmaking activity. Whether conducted within a paradigm based on "discovering" and "revealing" meaning, or one that posits the "creation" and the "construction" of meaning(s), social research is about generating meaning from data" (Leavy, 2015, hlm. 174) (Teknik seni visual sekarang digunakan dalam pendekatan metodologis untuk interpretasi).

Proses melakukan penelitian selalu merupakan kegiatan mengetahui makna. Apakah dilakukan dalam sebuah paradigma yang didasarkan pada "menemukan" dan "mengungkapkan" makna, atau salah satu yang berpendapat "penciptaan" dan "konstruksi" makna-makna, penelitian sosial adalah tentang menghasilkan makna dari data).
Berdasarkan definisi, menurut Encyclopedia of Art Education, definisi seni visual meliputi Fine Arts, Contemporary Arts, Decorative Arts \& Crafts, dan Applied Art areas. Karya seni visual Ngabandungan Banda Indung berdasarkan konsep visual dan teknis material yang digunakan masuk dalam salah satu kategori definisi visual art yaitu Decorative Arts $\mathcal{E}$ Crafts, visual dekoratif (batik) dan menggunakan teknik lukis kaca.

\section{HASIL DAN PEMBAHASAN}

\section{Indung dalam Kosmologi Sunda}

Kosmologi merupakan pembahasan matematis dan fisikal tentang alam semesta dan relevansinya dengan kehidupan modern. Djunatan (2013, hlm. 289) menjelaskan kosmologi merupakan elaborasi saintifik, falsafah, dan teologis tentang alam semesta yang berkaitan dengan keteraturan wilayah dalam manusia. Kosmologi juga merupakan kajian tentang hukum-hukum kekuasaan fisikal dan material yang menata alam semesta yang bersifat empirik dan rasional.

Pengetahuan urang Sunda mengenai semesta terdapat pada pola pikir pantun dan sewaka darma (Djunatan, 2013, hal. 293). Sumardjo (dalam Djunatan, 2013, hal. 293), menafsirkan kosmologi sunda dari pantun Mundinglaya Dikusumah dan Eyang Resi Handeula Wangi. Gambaran kosmologi Sunda yang terdapat pada pantun tersebut terdiri dari tiga buana yaitu Buana Nyungcung, Buana Panca Tengah dan Buana Larang. Penyebutan Sang Hyang Tunggal, Sang Hyang Kala, Sang Hyang Wenang, Sang Hyang Wening, Sang 
Hyang Guriang Tunggal pada pantun merujuk pada satu domain yang mulia. Sumardjo (2009, hal. 102), menjelaskan dalam kosmologi Baduy, terdapat mitologi asal usul keberadaan alam semesta yaitu adanya awang-awang dan uwung-uwungan, terdapat Batara Keresna, Batara Kawasa dan Batara Bima Mahakarana. Nama-nama tersebut bukanlah Tuhan dalam pengertian monoteisme, kosmologi Sunda dari pantun bukan gambaran hirarki tentang dunia, tapi bagaimana manusia tumbuh baik secara fisik maupun batin. Kepercayaan terhadap sang penguasa alam yang memberi kehidupan dikisahkan dalam bentuk pantun dan kisah-kisah mitologi lainnya.

Menurut Heryana (2006, hlm. 57-58), indung terbagi menjadi dua kategori yaitu indung biologis dan indung kultural. Indung biologis yaitu indung berkaitan dengan kodrat yang dimiliki perempuan dan peran perempuan dalam kehidupan rumah tangga. Indung sebagai Ibu memiliki sifatsifat perempuan seperti lemah lembut, kasih sayang, dan memiliki cikahuripan untuk anakanaknya. Indung kultural yaitu penyebutan indung yang ditujukan tidak hanya kepada manusia tetapi dapat ditujukan terhadap sesuatu, yang diambil dari indung ialah sifat keperempuanan, karakteristik indung yang terdapat pada diri perempuan. Karakter indung tersebut terdapat pada tokoh mitologi Sunan Ambu, Dayang Sumbi, dan Dewi Sri, dalam kisah mitologi tersebut juga menempatkan perempuan dalam posisi tertinggi.

Surya Saputra (dalam Heryana, 2006, hlm. 67) menuliskan mengenai spirit indung yang terdapat dalam siklus penciptaan manusia yang didasarkan pada kosmologi Sunda yang terdapat pada kepercayaan urang Kanekes Baduy Dalam. Urang Kanekes mempercayai adanya Ambu Langit (Sunan Ambu), Ambu Tengah dan Ambu Bumi sebagai perantara janin berada di rahim Ambu Simbarang Kandung (ibu). "Indung sama dengan Sunan Ambu, yang memiliki spirit dan kekuatan untuk menghidupkan manusia untuk memiliki semangat, cita-cita. Sunan Ambu menggerakkan spirit lahir dan batin. Sebagai manusia yang memiliki spirit indung harus hidup dengan dinamis dan bergerak" (Endang Caturwati, Komunikasi Pribadi. 28 Juni 2019).

Berkaitan dengan hal tersebut, dalam kosmologi Sunda indung dapat dikategorikan sebagai spirit yang memberi cikahuripan atau kehidupan yang terdapat pada tokoh mitologi Sunan Ambu, Dayang Sumbi, dan Dewi Sri, yang menempatkan perempuan dalam domain yang mulia. Sunan Ambu merupakan ibu kedewataan yang disembah, agung, yang penuh kuasa Sunan Ambu dianggap personifikasian dari Dewi Uma istri Siwa dalam agama Hindu (Adriati, 2001, hlm. 13). Sunan Ambu dianggap sebagai ibunda Keilahian yang merupakan Dewi kehidupan pemelihara penyelenggara keberadaan dan cinta kasih (Sumardjo dalam Adriati, 2001, hlm. 13)

\section{Pemuliaan Indung oleh Masyarakat Sunda}

Tohari, (2013, hlm. 21), menyatakan, Keberadaan perempuan dalam teks Sri Sadana menjadibuktipentingbahwasanyaalampikiran orang Sunda menempatkan perempuan pada posisi sentral. Hal tersebut berkaitan dengan 
pernyataan Jakob Sumardjo (dalam Listiani, 2013, hlm. 109), pada masyarakat primordial baik Sunda, Minangkabau, Batak, Melayu, Nias, Mentawai, Madura (tegalan), Nusa Tenggara, Maluku Selatan, Dayak, Sulawesi Utara, Sulawesi Tengah, dan Sulawesi Selatan menempati Dunia Atas sebagai entitas yang memiliki prinsip wanita.

Penyebutan indung lebih dominan, indung terdapat dalam paribasa Sunda, indung teruraikan dalam makna upacara adat tradisional pertanian, dalam mitos seperti sosok Sunan Ambu. Hal tersebut didasari oleh adanya pandangan - pandangan yang lebih menghargai indung (Heryana, 2006, hlm. 64-65). Menurut Enoch Atmadibrata (Heryana, 2012, hlm. 164-165), Pemuliaan indung oleh masyarakat Sunda tergambar pada tokoh-tokoh indung yang terdapat pada beberapa kisah mitologi, yaitu Sunan Ambu pada Gending Karesemen, Pohaci Sanghyang Sri sebagai waruga dari padi. Pada pantun Lutung Kasarung terdapat putri bungsu Purbasari, pada cerita Mundinglaya terdapat Dewi Asri, pada cerita Sangkuriang terdapat Dayang Sumbi, dalam pantun Nyi Sumur Bandung terdapat Nyi Sumur Bandung, dalam Wawacan Rengganis terdapat Rengganis, dalam wewengkon Garut terdapat Inten Dewata. Di Majalengka terdapat tokoh Nyi Rambut Kasih, menurut Saptono (2014, hlm. 30), Pada sekitar tahun 1480 M, di Desa Sindangkasih, Majalengka dikenal tokoh bernama Nyi Rambut Kasih. Kemuliaan indung juga terdapat di paribasa Sunda, diantaranya yaitu, Ngindung ka waktu ngabapa ka mangsa, Indung nu ngakandung bapa

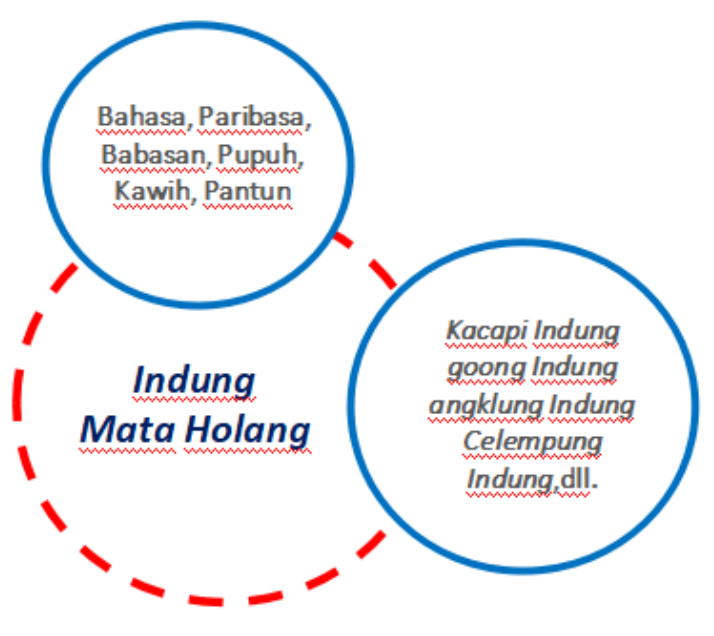

Gambar 1. Indung sebagai mata holang masyarakat Sunda

( Sumber : bagan dibuat oleh penulis, hasil interpretasi penulis terhadap pernyataan Heryana )

nu ngayuga, Indung tungguling rahayu bapa pujaning waluya.

Heryana (2012, hlm. 163), menyatakan, penyebutan indung dalam berbagai artefak kebudayaan Sunda sebagai pemuliaan indung merupakan mata holang atau idiom Sunda yang berarti sumber, pusat kehidupan atau ujung tombak dalam beraktivitas. Usaha memuliakan indung tidak hanya terdapat pada carita pantun atau paribasa, kata indung juga digunakan sebagai mata holang yang terdapat di berbagai artefak benda kebudayaan Sunda, seperti pada Waditra, yaitu sebutan untuk alatalat bunyi yang lazim dipergunakan sebagai alat musik tradisional Sunda (Kubarsah, 1994, hal. 1), seperti Angklung Indung, Calung Indung, dan Kacapi Indung.

\section{Pemuliaan Nyi Sri Pohaci di Masyarakat Desa Rancakalong}

Memuliakan indung oleh masyarakat Sunda juga diwujudkan dalam bentuk upacara tradisi pemujaan terhadap Nyi Sri Pohaci atau Sanghyang Sri. Berdasarkan 
wawancara kepada tokoh masyarakat Desa Rancakalong sebagai narasumber yaitu Bapak Jeje, pada 31 Maret 2019, masyarakat Desa Rancakalong masih melaksanakan tata cara pertanian dengan adat bertani Sunda, juga masih menjalankan upacara adat Ngalaksa hingga hari ini sebagai perwujudan syukur kepada Nyi Sri Pohaci atau Sanghyang Dewi Sri sebagai bagian dari perwujudan memuliakan indung. Tohari (2013, hal. 25), menyatakan penghormatan kepada Nyi Sri Pohaci atau Sanghyang Sri, ritual Tarawangsa, ritual Ngalaksa, Tradisi Mubur Suro, dll, yang semuanya itu berlandaskan kepada falsafah penghormatan terhadap perempuan. Menurut Rusyana, dalam situsnya https://kebudayaan. kemdikbud.go.id/bpnbjabar/upacaraadat-ngalaksa-di-kabupaten-sumedang/, “Ngalaksa merupakan upacara adat yang dilaksanakan masyarakat adat Rancakalong, Kecamatan Rancakalong". Awalnya Ngalaksa dilaksanakan oleh keluarga ditempat-tempat yang sunyi, jadwal pelaksanaannya dikaitkan dengan jadwal bersawah. Pada masa sekarang, pelaksanaan Ngalaksa dilaksanakan setiap tahun satu kali, diawal Bulan Juli. Upacara adat Ngalaksa dilaksanakan secara bergiliran oleh lima Rurukan yaitu : Rancakalong, Nagarawangi, Pamekaran, Pasir Biru, dan Cibunar, kemudian tempat pelaksanaanya di Desa Rancakalong. Makna dari upacara adat Ngalaksa ini didalamnya terkandung: wujud gotong royong, silaturahmi, persaudaraan, kesatuan dan persatuan, kerja sama, perwujudan rasa syukur kepada yang maha pencipta, sebagai penghormatan kepada para leluhur, serta sebagai ajang untuk

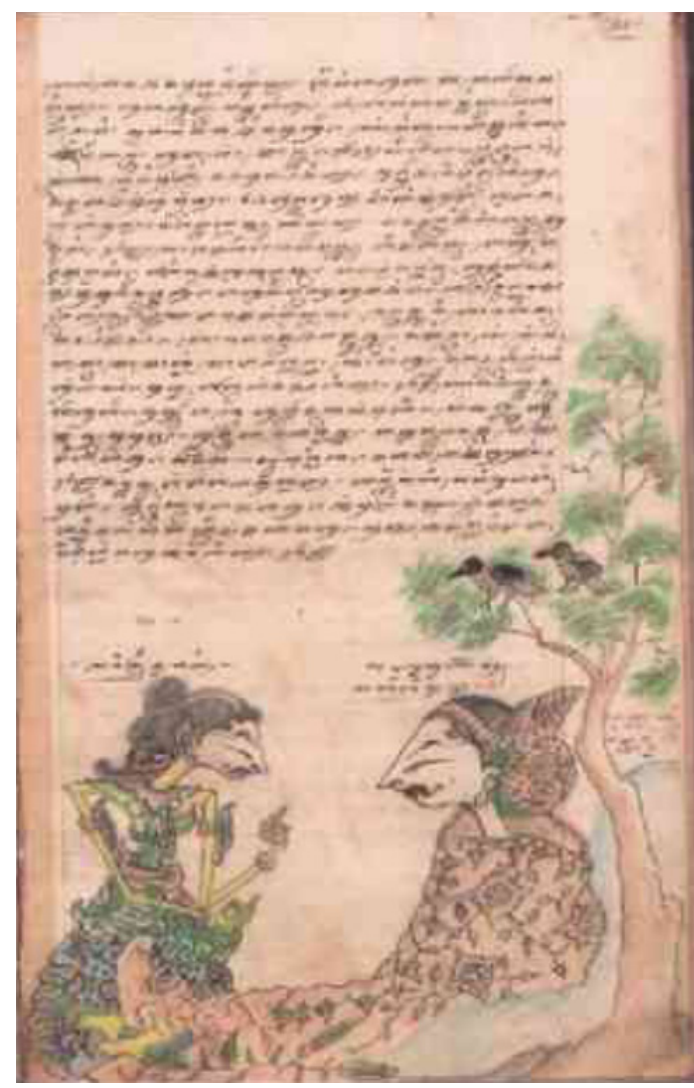

Gambar 2. Ilustrasi Dewi Sri atau Nyi Sri Pohaci pada naskah serat Satriya Budug Basu.

(Sumber : Ridwan, S., \& Abdulgani, F. (2012)

saling mengenal satu sama lain, (Rusyana, 2015,https://kebudayaan.kem dikbud. go.id/bpnbjabar/upacara-adat-ngalaksa-dikabupaten-sumedang/, 20 Mei 2015).

Falsafah yang terdapat dalam ritual Ngalaksa menurut Jeje (komunikasi pribadi. 31 Maret 2019), yaitu "Penghormatan terhadap Nyi Sri Pohaci sebagai pemberi kehidupan melalui tanaman paré (padi) sebagai bahan makanan pokok dan tanaman lainnya seperti honjé, jagung, kawung, kalapa, juga paré indung (bibit padi) dipercaya sebagai sumber kehidupan masyarakat Desa Rancakalong". Supriadi (2011, hal. 32), juga mengatakan, berdasarkan naskah Nyi Sri Pohaci, naskah tersebut membicarakan Dewi Sri yang menguasai ranah dunia bawah tanah juga bulan. Perannya mencakup segala aspek 


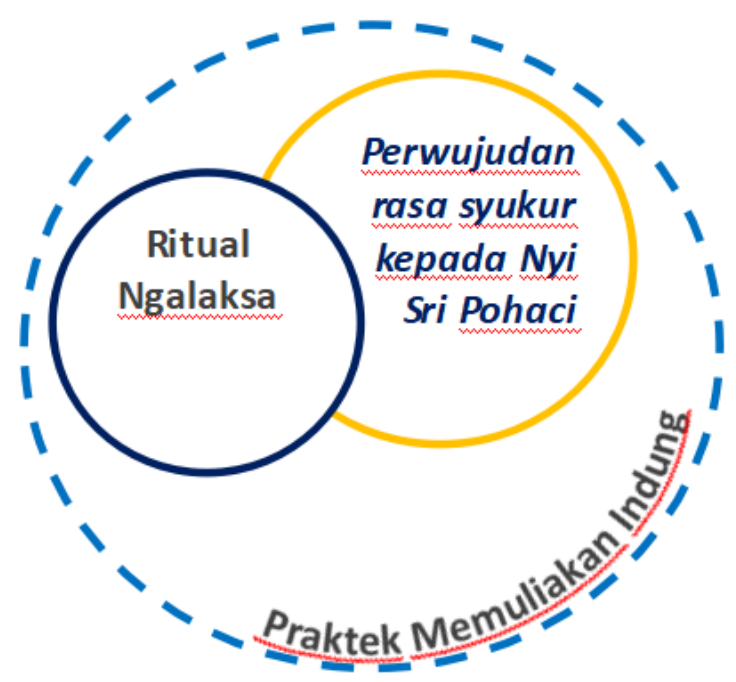

Gambar 3. Ritual Ngalaksa sebagai praktek memuliakan indung

(Sumber : bagan dibuat oleh penulis, hasil interpretasi penulis terhadap hasil hasil wawancara dengan Jeje, komunikasi pribadi, 31 Maret)

dewi ibu, yakni sebagai pelindung kelahiran dan kehidupan. Ia juga dapat mengendalikan bahan makanan di bumi terutama padi, maka ia mengatur kehidupan, kekayaan, dan kemakmuran karena ia merupakan simbol bagi padi, ia juga dipandang sebagai ibu kehidupan.

\section{Nyi Sri Pohaci dalam Karya Seni Visual}

Kisah Nyi Sri Pohaci dalam kisah mitologi telah menginspirasi banyak seniman untuk menginterpretasikannya dalam bentuk karya seni visual dan penamaan untuk judul karya pada umumnya menggunakan nama Dewi Sri. Judul Dewi Sri banyak ditemukan pada karya lukisan, antara lain, Sesadji Dewi Sri karya Ida Bagus Made Poleng tahun 1940 1964, Dewi Sri karya Srihadi Soedarsono tahun 1961, Dewi Sri karya Soedibio tahun 1971, Dewi Sri karya Otto Djaya tahun 1992, Dewi Sri karya Mahdi Abdullah tahun 1990, Dewi Sri (Goddess Sri) karya Irsam tahun 1996, Dewi Sri (Goddess of Rice and Fertility) karya Nasirun tahun 2005,

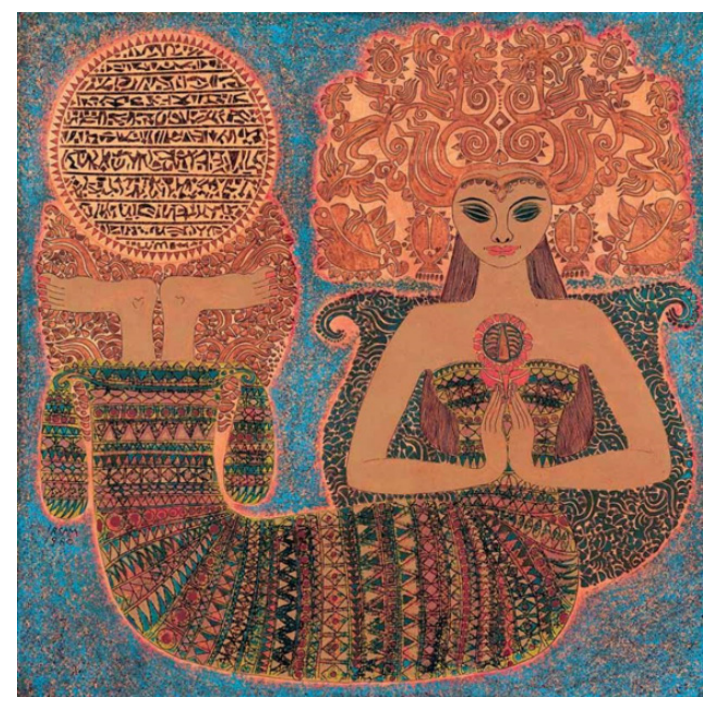

Gambar 4. Dewi Sri (Goddess Sri) - Irsam, cat minyak,kanvas, $100 \times 100 \mathrm{~cm}, 1980$.

(Sumber : Yura, 2018, https://lukisanku.id/lukisan-dewisri-goddess-sri-karya-irsam/ , 15 Oktober 2018)

dan Dewi Sri (Goddess Sri) karya Budi Asih tahun 2018 (Yura, 2018, https://lukisanku.id/ lukisan-dewi-sri/ , 15 Oktober 2018).

Selain karya lukis, tema-tema mengenai Nyi Sri Pohaci atau Dewi Sri juga terdapat pada Santap malam bersama Sri karya seni rupa pertunjukan karya Komunitas Padi, tahun 2001. Karya ini memiliki konsep seperti yang dinyatakan Komunitas padi, (2001) sebagai berikut; "Melihat ke dalam fenomena Kebudayaan Padi, perlu kiranya melandasi wacana alam pikiran dahulu ke dalam alam pikiran kini sebagai upaya yang sebenamya untuk melihat dan memahaminya secara esensial. Alam pikiran kultur padi, dengan demikian dapat dikenali melalui mitosmitos yang berkembang di dalam kehidupan masyarakat-padi (desa) yang terlihat acapkali di dalam aktivitas ritual mereka atau dari moral etika ataupun tingkah laku masyarakatnya sebagaimana fungsi mitos di dalam kehidupan sehari-hari masyarakat tradisional. Suatu masyarakat holistik: dimana 
mereka mempercayai adanya kekuatan (kehidupan) lain selain kehidupan manusia (Jagad Besar dan Jagad kecil)". (Komunitas Padi, 2001)

Penciptaan karya seni yang mengangkat tema mitologi khususnya Dewi Sri atau Nyi Sri Pohaci masih sangat relevan dengan fenomena kehidupan budaya masyarakat hari ini, seniman sebagai agen kebudayaan melalui karya seninya berupaya dalam menguatkan identitas budaya melalui tema-tema mitologi dan tema kebudayaan lainnya. Mengenai hal tersebut, Mikke Susanto mengatakan “Sesungguhnya yang mampu mengelola mitos adalah seniman. Seniman tidak ada di satu titik tertentu. Bisa di wilayah sains, agama, mitos yang hari ini muncul" (Ramadhan, 2019, https://www.medcom.id/pendidikan/ news-pendidikan/yNL7goPK-triennalebasuki-abdullah-art-award-usung-temaremitologisasi, 24September 2019). Pernyataan tersebut juga dipertegas oleh Irawan Karseno, "mitos ini penting untuk ditafsir ulang. Karena masih menjadi problematik sekarang ini" (Ramadhan, 2019, https://www.medcom. id/pendidikan/news-pendidikan/yNL7goPKtriennale-basuki-abdullah-art-award-usungtema-remitologisasi , 24 September 2019). Melalui karya seni visual yang diciptakan oleh seniman, tema Nyi Sri Pohaci atau Dewi Sri dapat mengembalikan masyarakat pada pola pikir budaya sebagai identitasnya.

\section{Ngabandungan Banda Indung Karya Seni} Visual sebagai Interpretasi Nyi Sri Pohaci.

Ngabandungan Banda Indung merupakan karya seni visual yang dibuat berdasarkan penelitian, hasil interpretasi dari studi literatur dan wawancara dengan Bapak Jeje selaku tokoh Desa Rancakalong, wawancara yang dilakukan mengenai simbol dan makna indung yang terdapat pada falsafah masyarakat Desa Rancakalong. Karya merupakan interpretasi dari pemahaman makna indung yang terkandung dalam falsafah masyarakat Rancakalong, sebagai tujuan dari dibuatnya karya seni visual Ngabandungan Banda Indung. Mencari indung adalah upaya untuk mencari tahu simbol dan makna indung dalam budaya Sunda, untuk kemudian dituangkan ke dalam bentuk karya seni visual. Falsafah tersebut tertuang dalam pantun Masyarakat Rancakalong yang diungkapkan oleh Bapa Jeje dari hasil wawancara, sebagai berikut:

"Paré raranggeuyan, dina paré aya kapatrian aya kamahian, melakna dititipkeun ka nu ngersakeun, jembarna ka para karuhun ka nu mipuhun, ngamitkeun badé ngalana. Kersa Nyai Sri, landung aisan, laér cancangan, lega sampalan, sakedik pati, loba nyésa, awét dianggo kumawulana, Narima tumarima nunarima, usik paparieun, obah paréntah raga tanpa polah, ti Gusti nu Maha Suci" (Jeje, komunikasi pribadi. 31 Maret 2019).

Garis besar dari arti falsafah pada pantun tersebut sebagai berikut: Dalam tanaman padi yang berjuntai, terdapat kepastian dan kecukupan, yang ditanam dengan doa kepada yang berkehendak dan leluhur, memohon izin untuk dipanen. Atas kehendak Nyai Sri dalam tanaman padi terdapat keberkahan.

$$
\text { Paré (padi) dalam kepercayaan }
$$
masyarakat Desa Rancakalong menurut nara sumber merupakan perwujudan dari Nyi Sri Pohaci sebagai salah satu banda indung 
(kekayaan ibu). Pada kepercayaan budaya Sunda, paré (padi) tidak dapat dilepaskan dengan kekayaan lainnya, seperti honje, jagong, kalapa dan kawung. Dalam budaya Sunda segala sesuatu yang berada di alam adalah banda indung (kekayaan ibu). Merenungi Nyai Sri Pohaci dapat membawa diri ke arah kesempurnaan atau keseimbangan hidup, sehingga manusia yang mau berfikir menjadi perlu untuk ngabandungan banda Indung (Jeje, komunikasi pribadi. 31 Maret 2019).

Hasil wawancara tersebut dijadikan sebagai konsep berkarya. Karya ini telah dipamerkan di International Art Exhibition yang bertajuk Reinterpretation of Mooi Indie di Galeri R FSRD Universitas Trisakti Jakarta pada 26 April hingga 10 Mei 2019. Karya Ngabandungan Banda Indung menggunakan media Lukisan Kaca (Glass Painting), ukuran 50x50cm, tahun pembuatan 2019.

Karya Seni Visual Ngabandungan Banda Indung, menginterpretasikan indung dalam bentuk padi sebagai perwujudan dari Nyi Sri Pohaci. Interpretation is the revenge of the intellectual upon art. - Susan Sontag (dalam Leavy, 2015, hlm. 189).

Indung dalam hal ini adalah indung kultural yang didefinisikan oleh Heryana (2006, hlm. 57-58) lihat pada hasil dan pembahasan paragraf 3. Dalam hal ini Adriati (2001, hlm. 13), menuturkan Pohaci yang berarti pwah aci yaitu sari atau inti keperempuanan maupun hakiki keperempuanan, merupakan pelaksana perintah Sunan Ambu ke bumi manusia di panca tengah untuk menjaga dan memelihara kebutuhan-kebutuhan manusia yang terdiri dari sandang, pangan, dan papan.

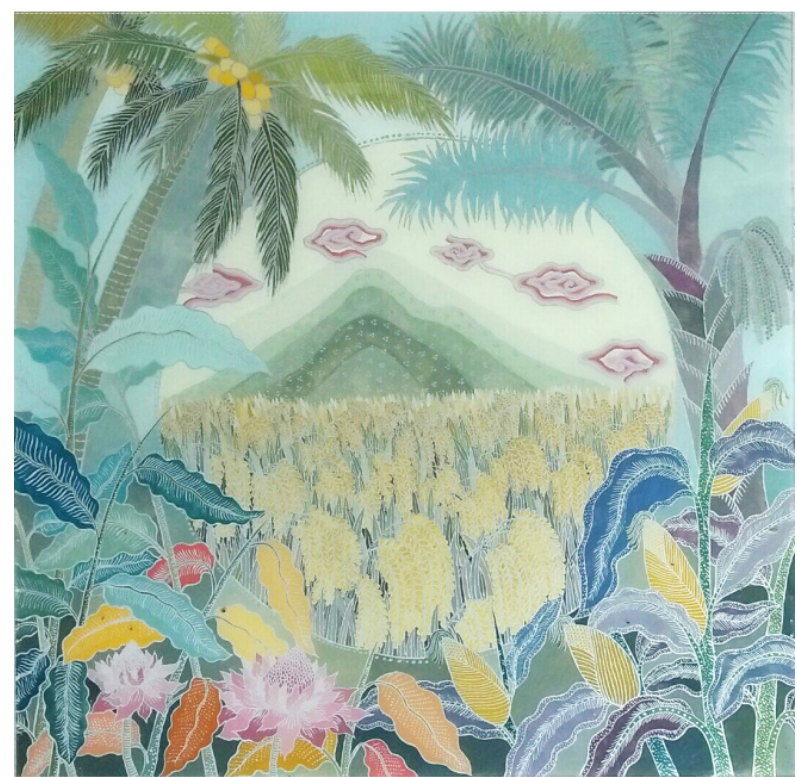

Gambar 5. Ngabandungan Banda Indung Lukisan Kaca 50x50cm, Tahun 2019

Visualisasi dalam karya Ngabandungan Banda Indung, selain menginterpretasikan kekayaan alam Desa Rancakalong hasil penelitian juga menggambarkan pemandangan alam menggunakan konsep estetika dalam budaya rupa Sunda yang bersumber dari kondisi alam Sunda dan sastra Sunda. Konsep keindahan masyarakat Sunda memiliki hubungan antara rekaan dan alam. Pemandangan alam bagi masyarakat Sunda bersifat reflektif dan spiritual. Kondisi alam yang indah menciptakan masyarakat yang dalam khasanah bahasanya memiliki perbendaharaan kata yang khas yaitu waas (Wiartakusumah dalam Jamaludin, 2011, hal. 3). Berdasarkan falsafah masyarakat Desa Rancakalong dan estetika Sunda tersebut, pada karya seni visual Ngabandungan Banda Indung digambarkan lanskap pemandangan alam, pada komposisi dibagian tengah karya digambarkan tanaman padi di pesawahan sebagai objek utama dari konsep karya yaitu tanaman paré (padi) atau Nyai Sri, dengan 
latar belakang gunung, awan, dan langit. Pada setiap sisi digambarkan tanaman honje, jagung, pohon kawung, dan kelapa sebagai perwakilan dari keragaman hayati lainnya. Penggambaran lanskap oleh masyarakat Baduy memiliki istilah untuk menyebutkan keindahan pada objek-objek rupa dengan sebutan pamandangan. Pamandangan juga berarti sarupaning anu katingalnaéndah (Prawira dalam Jamaludin, 2011, hlm. 3).

Selain menggambarkan pemandangan juga menggunakan gaya visual batik sebagai konsep estetika Sunda, konsep estetik Sunda juga terdapat pada ragam hias batik Sunda (priangan). Aspek estetik ragam hias Sunda memiliki nilai-nilai kearifan lokal budaya Sunda. Di dalam batik Sunda terdapat kosakata lokal yang menjelaskan hal baik dan indah (estetik) seperti wirahma (irama), saimbang (seimbang), henteu silung (harmoni), henteu garihal (tidak kasar, halus), pantes/ pasieup (pantas) dan lainnya (Sunarya, 2018, hlm. 34). Batik sebagai artefak budaya Sunda merupakan identitas masyarakat Sunda. Sunarya (2018, hlm. 40), menyatakan; setiap masyarakat Sunda baik secara sadar maupun tidak sadar, mengembangkan produk batiknya sebagai ungkapan dan pernyataan rasa estetik yang merangsangnya sejalan dengan pandangan, aspirasi, kebutuhan dan gagasan yang mendominasinya.

Penggunaan warna dalam karya ini menggunakan warna yang terdapat pada budaya Sunda. "Color in Sundanese culture is an important element so that the Sundanese understand, interpret, and use color as part of everyday life" (Warna dalam budaya Sunda merupakan unsur penting sehingga orang Sunda memahami, menafsirkan, dan menggunakan warna sebagai bagian dari kehidupan sehari-hari). (Maulina dan Sabana, 2018, hlm. 395). Warna dalam budaya Sunda memiliki dimensi.

"in Sundanese culture there are also other color dimensions such as dimensions of color naming, dimensions of meaning, and dimensions of color usage as communication tools. These dimensions describe theattributes found in Sundanese culture."

(Warna dalam budaya Sunda selain digunakan sebagai nilai keindahan, juga memiliki dimensi lain, seperti penamaan warna, makna, dan penggunaan warna sebagai alat komunikasi. Dimensi ini menggambarkan atribut yang ditemukan dalam budaya Sunda) (Maulina dan Sabana, 2018, hlm. 396). Teknik pewarnaan menggunakan cat minyak pada permukaan kaca, mengadopsi teknik lukisan kaca Cirebon. Dalam pembuatan karya Ngabandungan Banda Indung, baik gagasan pemikiran maupun gagasan estetik dan material berdasarkan dari kebudayaan Sunda, seperti ungkapan Ajip Rosidi (dalam Hudaya, 2009, hlm. 369), Manusia Sunda adalah manusia yang berbuat dan berpikir dengan berpijak pada nilai-nilai budaya Sunda.

\section{PENUTUP}

Indung dalam kosmologi Sunda diantaranya terdapat pada tokoh-tokoh mitologi yang memiliki karakterisik indung seperti Sunan Ambu, Dayang Sumbi, dan Nyi Sri Pohaci. Tokoh- tokoh tersebut dipercayai 
sebagai pemberi kehidupan. Tokoh-tokoh tersebut menjadi sosok sentral spiritual masyarakat Sunda dan ditempatkan pada kedudukan tertinggi, seperti ungkapkan Tohari, bahwa indung menjadi simbol kesempurnaan bagi pencapaian spiritualitas yang dihayati dalam kehidupan sehari-hari sebagai tindakan memuliakan indung. Hal ini terlihat pada upacara adat Ngalaksa yang dilakukan oleh masyarakat Sunda Desa Rancakalong, sebagai bentuk penghormatan terhadap Nyi Sri Pohaci sebagai praktek memuliakan indung .

Upacara adat Ngalaksa mengandung falsafah masyarakat Desa Rancakalong, yaitu memaknai kekayaan alam sebagai banda indung (kekayaan ibu) yang patut dijaga dan disyukuri, dan memuliakan Nyi Sri Pohaci sebagai indung, sebagai capaian spiritualitas, sebagai tindakan membawa diri ke arah kesempurnaan atau keseimbangan hidup, bagaimana manusia tumbuh baik secara fisik maupun batin melalui pemujaan dan penghormatan kepada pemberi kehidupan.

Paré (tanaman padi) yang dipercaya oleh masyarakat Rancakalong sebagai perwujudan dari Nyi Sri Pohaci yang dipercaya sebagai pemberi kehidupan, ialah spirit indung, yaitu karakteristik indung yang terdapat pada diri perempuan terdapat pada tokoh mitologi Sunda, juga pada ungkapan Adriati, Pohaci yang berarti sari atau inti keperempuanan maupun hakiki keperempuanan. Kandungan indung yang terdapat pada tokoh Nyi Sri Pohaci dan falsafah masyarakat Desa Rancakalong mewujud dalam bentuk simbol, maknanya tidak terlihat jelas, dan maknanya perlu dipahami seperti diungkapkan oleh Prawira, bahwa adat istiadat dan benda-benda sebagai artefak sarat dengan muatan simbol, yang apabila ingin mengetahui dan memahami simbol tersebut harus dicari maknanya.

Karya seni visual Ngabandungan Banda Indung (merenungi kekayaan ibu) dibuat sebagai interpretasi dari pemaknaan indung yang terdapat pada falsafah masyarakat Desa Rancakalong. Memvisualkan kekayaan alam sebagai banda indung melalui penggambaran lanskap pemandangan alam dengan menggunakan konsep estetika Sunda seperti yang diungkapkan oleh Prawira, masyarakat Baduy menyebutkan keindahan pada objekobjek rupa dengan istilah pamandangan, sarupaning anu katingalna endah (hal-hal yang terlihat indah), dengan gaya visual batik priangan, seperti ungkapan Sunarya, batik merupakan ungakapan dan pernyataan rasa estetik dan sebagai identitas masyarakat Sunda. Ngabandungan Banda Indung sebagai renungan terhadap indung yang memberi kehidupan melalui karya seni visual.

\section{Ucapan Terima Kasih}

Terima kasih diucapkan kepada Rektor Universitas Komputer Indonesia, atas dukungannya untuk penelitian ini.

\section{Daftar Pustaka}

Adriati, Ira. (2001). Kultur Padi: Menelusuri Penghormatan Terhadap Nyi Pohaci Sanghyang Sri. Museum Nasional. http://repositori.kemdikbud. 
go.id/10928/1/kultur\%20padi.pdf

Art Encyclopedia Visual Arts of Painting: Sculpture: Architecture Photography: Ceramics and other crafts. (n.d.). Retrieved from http://www.visual-artscork.com/

Djunatan, Stephanus. (2013): Kekosongan yang Penuh: Sebuah Tafsiran Atas Kosmologi Sunda. Melintas. 29.3.2013 (288-314).

Heryana, Agus. (2006): Indung, Konsep dan Aktualitas Perempuan Sunda. Balai Pelestarian Nilai Budaya, Bandung.

Heryana, Agus. (2012): Mitologi Perempuan Sunda. Patanjala Vol. 4 No. 1. https:// commons.wikimedia.org/wiki/ File:Indonesia_West_Java_location_ map.svg

Hudaya, D., Rahayu, L. M., \& Hazbini, H. H. (2015). Aktualisasi Mitos "Sangkuriang" dan "Lutung Kasarung" dalam Novel "Déng" Karya Godi Suwarna. Panggung, 25(4). doi: 10.26742/panggung.v25i4.44

Jamaludin. (2011): Konsep Estetika dalam Budaya Rupa Sunda Sebuah Kajian Awal. International Seminar on Reforming and Transforming Sundanese Culture. Faculty of Letters Universitas Padjadjaran. Jatinangor, 9-10 Januari. http://lib.itenas.ac.id/kti/ wp-content/uploads/2012/03/makalahKonsep-Estetika-Sunda-unpad.pdf

Komunitas padi. (2001). Santap Malam Bersama Sri Pendekatan Karya : Antropologis, Etnografis, Sosiologis. Museum Nasional. http://repositori. kemdikbud.go.id/10928/1/kultur\%20 padi.pdf

Leavy, Patricia. (2015): Second Edition, Method Meets Art, Art Based Research Practice. The Guilford Press. New York. London. Leavy, P. (2013). Fiction as research practice: Short stories, novellas, and novels. Walnut Creek, CA: Left Coast Press

Listiani, W., Ahimsa-Putra, H. S., Lonolastorosimatupang, G., \& Piliang, Y. A. P. A. (2013). Regenerative-Relational Tritangtu: Sundanese Triadic Transformation Model. Panggung, 23(2). doi: 10.26742/ panggung.v23i2.91

Maulina, Rini dan Sabana, Setiawan. (2018): Sundanese Colors. Proceeding of International Conference on Business, Economic, Social Science and Humanities (ICOBEST 2018). ISBN 97894-6252-611-2. https://doi.org/10.2991/ icobest-18.2018.77

Prawira, Nanang Ganda. (2017): Pamandangan Reka Hias Baduy:Fungsi, Bentuk, Motif, Simbol, di Desa Kanekes, Kecamatan Leuwidamar, Kabupaten Lebak, Jawa Barat. Bintang warli Artika, Bandung.

Ramadhan, S.M. (2019, September 24). Triennale Basuki Abdullah art award Usung Tema Remitologisasi. medcom.id. https://www.medcom. $\mathrm{id} /$ pendidikan/news-pendidikan/ yNL7goPK-triennale-basuki-abdullahart-award-usung-tema-remitologisasi

Ridwan, S., \& Abdulgani, F. (2012). Penulisan Cerita Budug Basu di Kalangan Keraton Cirebon. Manuskripta, Vol.2 No. 1, 119138. doi:10.33656/manuskripta.v2i1.30

Rosidi, Ajip. (2005): Babasan \& Paribasa: Kabeungharan Basa Sunda. Kiblat Buku Utama. Bandung.

Rusyana. (2016, December 8). bpnbbandung. Retrieved from https://kebudayaan. kemdikbud.go.id/bpnbjabar/ upacara-adat-ngalaksa-di-kabupatensumedang/

Saptono, N. (2014). Geografis Kota Majalengka dalam Kaitannya dengan Konsep Bentuk Lahan dan Tata Kota. City of Majalengka Geographic in Conjunction with Landform and Lay Out. PURBAWIDYA: Jurnal Penelitian Dan Pengembangan Arkeologi, 3(1), 27. doi: 10.24164/pw.v3i1.5

Sumardjo, Jakob. (2009): Kosmologi dan Pola Tiga Sunda. Jurnal Imaji. Vol.4. No. 2. Web 01-09-2018.

Sunarya, Yan yan. (2018). Adaptasi Unsur Estetik Sunda pada Wujud Ragam Hias Batik Sunda. Jurnal Visual Art. Vol. 10 No. 1 (27-51). ITB Journal Publisher. ISSN: 2337-5795. DOI: 10.5614/j. vad.2018.10.1.3

Supriadi, Dedi. (2011). Tradisi Pembacaan Naskah Nyi Sri Pohaci di Desa 
Rancakalong, Kabupaten Sumedang, Jawa Barat. Manuskripta, 1(2), 31-41. doi:10.33656/manuskripta.v1i2.16

Tohari, Heri Mohamad. (2013): Feminisme Sunda Kuno: Studi Interpretasi Kritis Akulturasi Nilai-nilai Kesetaraan Gender Sunda-Islam Dalam Carita Pantun Sri Sadana. Jurnal Etika dan Pekerti. Vol. 1. No. 2

Yura, Alya (2018). Lukisan “Dewi Sri” (2018, October 15). Informasi Lukisan Indonesia. https://lukisanku.id/ lukisan-dewi-sri/ 